\title{
CORRELATION BETWEEN HYPERTENSION AND LIPID PROFILE IN PATIENTS WITH TYPE 2 DIABETES MELLITUS AT PIRNGADI HOSPITAL, MEDAN, NORTH SUMATERA
}

\author{
Jekson Martiar Siahaan'), Endy Julianto's), \\ Hendrika Andriana Silitonga ${ }^{3}$ )
}

\author{
1)Department of Physiology, Faculty of Medicine, Methodist University, Medan \\ 2)Department of Parasitology, Faculty of Medicine, Methodist University, Medan \\ 3)Department of Histology, Faculty of Medicine, Methodist University, Medan
}

\begin{abstract}
Background: Dyslipidemia, hypertension, and type 2 Diabetes Mellitus (type 2DM) have been identified as early predictors of cardiovascular disease. Hypertension is a common disease in patients with type 2-DM. Dyslipidemia is a major risk factor for atherosclerosis. Type 2-DM and hypertension are risk factors for atherosclerotic lesions associated with dyslipidemia. Hypertension is associated with blood lipid disorders in many ways and contributes to the overall risk of cardiovascular disease. This study aimed to determine the correlation between hypertension and lipid profile in patients with type 2-DM at Pirngadi hospital, Medan, North Sumatera.

Subjects and Method: This was an analytic observational study with a crosssectional design conducted at endocrinology polyclinic Pirngadi Hospital, Medan, North Sumatera, from December 2017 to January 2018. A sample of 15 hypertension patients was selected for this study. The dependent variable was lipid profile. The independent variables were systolic and diastolic blood pressures. Lipid profile was measured by blood serum examination. The data were analyzed by Pearson correlation.

Results: Systolic blood pressure (SBP) increased with total cholesterol level ( $\mathrm{r}=$ 0.33; $\mathrm{p}=0.233$ ), LDL level $(\mathrm{r}=0.25 ; \mathrm{p}=0.377)$, HDL level $(\mathrm{r}=0.40 ; \mathrm{p}=0.137)$. Systolic blood pressure was not associated with triglyceride level $(\mathrm{r}=0.02$; $\mathrm{p}=0.936)$. Diastolic blood pressure increased with total cholesterol level $(\mathrm{r}=0.40$; $\mathrm{p}=0.143)$, LDL level $(\mathrm{r}=0.15 ; \mathrm{p}=0.589)$, HDL level $(\mathrm{r}=0.27 ; \mathrm{p}=0.326)$, and triglyceride level $(\mathrm{r}=0.37 ; \mathrm{p}=0.174)$.

Conclusion: This study concludes that there is a relationship between hypertension and lipid profile in patients with type 2 Diabetes Mellitus, but not statistically significant. There is a need to conduct a further study with a larger sample.
\end{abstract}

Keywords: type 2 diabetes mellitus, blood pressure, lipid profile

Correspondence:

Jekson Martiar Siahaan. Department of Physiology, Faculty of Medicine, Methodist University, Medan.

Mid-International Conference on Public Health, Best Western Premier Hotel, Solo, Indonesia, 18-19 April 2018 | 247 https://doi.org/10.26911/mid.icph.2018.05.09 